\title{
Let's Get Real about Person- and Family-Centred Geriatric Home Care: A Realist Synthesis
}

\author{
Justine L. Giosa, ${ }^{1,2}$ Paul Holyoke, ${ }^{2}$ and Paul Stolee ${ }^{1}$
}

\begin{abstract}
RÉSUMÉ
Cette étude a examiné les mécanismes complexes intervenant lors de la prestation de soins axés sur la personne et la famille (SAPF) par des équipes de soins gériatriques à domicile. Une approche par synthèse réaliste a été utilisée pour élaborer un cadre d'évaluation qui a inclus 159 références provenant de la littérature scientifique, des consultations d'experts canadiens en SAPF, des recherches ciblées dans les bases PubMed/MEDLINE ${ }^{\circledR}$ et CINAHL, et des recensions de la littérature grise canadienne. Les références ont été sélectionnées par deux personnes, selon une approche consensuelle avec évaluation de la qualité. Les données ont été extraites et synthétisées en tenant compte du contexte, des mécanismes et des configurations des résultats dans un cadre théorique de SAPF d'équipe pour les soins gériatriques à domicile. Le cadre présente les contributions spécifiques prédominantes des infirmières, des ergothérapeutes et des physiothérapeutes, leurs apports collectifs impliquant des communications pour des équipes virtuelles, ainsi que le soutien du système nécessité pour la prestation de SAPF d'équipe complets. Les résultats de cette étude pourraient contribuer à l'amélioration de l'éducation sur les SAPF et des lignes directrices sur les pratiques exemplaires, en vue d'assurer une prestation plus intégrée des SAPF dans les soins gériatriques offerts à domicile ou dans d'autres milieux comportant des équipes de soins.
\end{abstract}

\section{ABSTRACT}

This study investigated the complex mechanisms underlying team-based delivery of person- and family-centred care (PFCC) in geriatric home care. Using a realist synthesis approach, an evaluative framework was developed and populated with 159 references from scoping the literature, consulting Canadian experts in PFCC, purposive searching in PubMed/MEDLINE ${ }^{\circledR}$ and Cumulative Index to Nursing and Allied Health Literature (CINAHL), and reviewing grey literature within Canada. References were selected using a two-person review and/or consensus approach and quality appraisal. Data were extracted and synthesized using context, mechanism, and outcome configurations into a theoretical framework of team-based PFCC in geriatric home care. The framework details the predominant discipline-specific contributions of nurses, occupational therapists, and physiotherapists, their collective contributions through communication in the context of a virtual team, and the system-level support required for comprehensive team-based PFCC delivery. Findings from this study could inform improvements to PFCC education, best practice guidelines, and more integrated delivery of PFCC in geriatric home care and other team-based care environments.

1 School of Public Health and Health Systems, University of Waterloo, Waterloo, Ontario.

2 SE Research Centre, Markham, Ontario.

* Justine L. Giosa acknowledges the following individuals for their support in completing this knowledge synthesis: Grace Lui, Danielle Bender, Seham Rabaa, Shilpi Majumder, Steven Mock, Nancy Pearce, and Jackie Stapleton. This work was supported by the Canadian Institutes of Health Research Sir Frederick Banting and Charles Best Canada Graduate Scholarship-Doctoral Award.

Manuscript received: / manuscrit reçu : 07/03/18

Manuscript accepted: / manuscrit accepté : 29/11/18

Mots-clés : vieillissement, soins axés sur la personne et la famille, équipes interdisciplinaires, soins à domicile, gériatrie, synthèse réaliste

Keywords: aging, person- and family-centred care, interdisciplinary teams, home care, geriatrics, realist synthesis

Canadian Journal on Aging / La Revue canadienne du vieillissement 38 (4) : 449-467 (2019)

Copyright (C) Canadian Association on Gerontology 2019. This is an Open Access article, distributed under the terms of the Creative Commons Attribution licence (http://creativecommons.org/licenses/by/4.0/), which permits unrestricted re-use, distribution, and reproduction in any medium, provided the original work is properly cited. 
La correspondance et les demandes de tirés-à-part doivent être adressées à : / Correspondence and requests for offprints should be sent to:

Justine L. Giosa, PhD

School of Public Health and Health Systems

University of Waterloo

200 University Avenue West

Waterloo, ON N2L 3G1

Canada

(jgiosa@uwaterloo.ca)

\section{Introduction}

Person- and family-centred care (PFCC) is a wellestablished philosophy of care in health care literature and discourse. PFCC involves mutually beneficial partnerships among patients, family/friend caregivers, and health care providers to plan, deliver, and monitor health and social care services that meet and respond to individual needs and preferences (Ball, 2010; Epstein \& Street, 2011; Institute for Patient and Family-Centred Care, 2010, para. 1). Since the 1980s, PFCC has been a primary driver in a culture shift away from traditional hierarchical, clinician-centred medicine towards empowering patients and families as active partners in their health and care; acknowledging them as individuals with unique needs, desires, family situations, and values; and working together with them to make decisions about their care (Adams \& Drake, 2006; Bender \& Holyoke, 2016; de Haes, 2006; Expert Group on Home and Community Care, 2015; Johnson et al., 2008; McCance, McCormack, \& Dewing, 2011).

Although variations exist in the terminology used to describe PFCC (e.g., patient-centred care, client-centred care, client-focused care, relationship-centered care, consumer-directed care) (Cott, 2004; DiLollo \& Favreau, 2010; Edvardsson \& Innes, 2010; Edvardsson, Winblad, \& Sandman, 2008) and there is no universal definition of the term (Kitson, Marshall, Bassett, \& Zeitz, 2013; McCance et al., 2011), The Institute for Patient and Family-Centred Care (2010) describes PFCC as involving the following four key concepts:

- Dignity and Respect: Health care practitioners listen to and honour patient and family perspectives and choices. Patient and family knowledge, values, beliefs, and cultural backgrounds are incorporated into the planning and delivery of care.

- Information Sharing: Health care practitioners communicate and share complete and unbiased information with patients and families in ways that are affirming and useful. Patients and families receive timely, complete, and accurate information in order to effectively participate in care and decision making.

- Participation: Patients and families are encouraged and supported in participating in care and decision making at the level they choose.

- Collaboration: Patients, families, health care practitioners, and leaders collaborate in policy and program development, implementation, and evaluation; in health care facility design; and in professional education, as well as in the delivery of care (Institute for Patient and FamilyCentred Care [2010] para. 4).

The Institute for Patient and Family-Centred Care definition of PFCC has been widely adopted and used to describe clinical and health services interventions (Gladman, Jones, Radford, Walker, \& Rothera, 2007; Gustafsson et al., 2015; Snayde \& Moriarty, 2009), best practice guidelines (Registered Nurses Association of Ontario, 2015) and mission statements of organizations across the continuum of care (Bender \& Holyoke, 2016; Holland-Bloorview Kids Rehabilitation Hospital, 2013; North York General Hospital, 2015; Providence Healthcare, 2015; Saint Elizabeth Health Care, 2015a). Beyond its descriptive uses, PFCC has been shown to lead to improved outcomes at the point-of-care including increased quality, satisfaction, and functional ability from the perspective of patients, family/friend caregivers, and providers (Beech, Ong, Jones, \& Edwards, 2017; Bender \& Holyoke, 2016). Although these findings are promising, most of the progress in PFCC care delivery to date has been made and described within the context of interactions between individual health care providers and patients and/or their families, despite the reality that today's health care system centres on team-based care provision, where more than one different type of provider is involved at any given time (Beech et al., 2017; Cott, 2004; Hobbs, 2009). These individual conceptualizations are usually health discipline specific, with different types of providers operationalizing PFCC based on their unique scopes of practice, world-views, philosophies, and goals for patient care (Cott, 2004; Cott et al., 2001; Dow, Haralambous, Bremner, \& Fearn, 2006; Hobbs, 2009; Moe, Ingstad \& Brataas, 2017). For example, nurses work within a bio-psycho-social-spiritual model of health, occupational therapists (OTs) focus on a holistic view of patient health, and physiotherapists (PTs) apply a bio-psycho-social model of health (McCallin \& McCallin, 2009). Multiple discipline-specific theories exist for describing PFCC, and their tailored focus and specificity limit their individual applicability for guiding teambased PFCC (Cott, 2004; Hobbs, 2009).

As collaborative, team-based care has become a standard in good quality patient health care (McCallin \& McCallin, 
2009), it is essential to find strategies to support and guide the implementation of comprehensive, team-based PFCC, particularly in health care situations and settings that almost always require multidisciplinary patient care, such as geriatric home care (Cott, 2004; Cott, Wiles, \& Devitt, 2007). Older adults tend to have multiple health issues with physical, functional, cognitive, and psychosocial dimensions, and they require care from multiple types of providers, using a variety of approaches and treatments (Coleman, 2003; Coleman \& Boult, 2003; Covinsky, Palmer, \& Fortinsky, 2003; The Change Foundation, 2011; Toscan, Mairs, Hinton, \& Stolee, 2012; Welsh, Gordon, \& Gladman, 2014). This interdisciplinary care is even more complicated in the home care setting, as providers do not share time and space in the delivery of care to patients as they might in an institutional setting.

Previous reviews of the literature have focused on describing broad PFCC strategies (Brookman, Jakob, DeCicco, \& Bender, 2011; Department of Health and Human Services, 2006; Kane et al., 2015), or have homed in on explaining interdisciplinary teamwork (Hewitt et al., 2015; Hewitt, Sims, \& Harris, 2014) but there is a lack of understanding of how these two concepts come together within the reality of geriatric home care. Personand family-centred geriatric home care requires thinking beyond descriptive, overarching concepts of PFCC and silos of individual discipline-specific theories to understand how, why, and in what circumstances these concepts and theories do and/or should interact in an interdisciplinary team environment. The purpose of this study was to review available knowledge and evidence on how, why, and in what circumstances interdisciplinary geriatric home health care teams deliver team-based PFCC. The specific research questions that guided the study were:

1. What are the contexts and underlying mechanisms needed to achieve Respect and Dignity, Information Sharing, Participation, and Collaboration in team-based geriatric home care?

2. How do interdisciplinary geriatric home health care team members individually and collectively participate in team-based PFCC?

\section{Methods}

A realist synthesis method was used to carry out this work. Realist synthesis is a knowledge synthesis approach that seeks to uncover and understand the mechanisms behind complex interventions to understand how they work or why they fail, in particular social contexts (Kastner et al., 2011; Pawson, Greenhalgh, Harvey, \& Walsh, 2004; Wong, Greenhalgh, Westhorp, Buckingham, \& Pawson, 2013). Realist synthesis can be considered to sit between scoping review methods and systematic review methods of knowledge synthesis in terms of the flexibility of the approach. Major differences between these three knowledge synthesis methods exist in terms of overall goal, search strategy, quality assessment, and implementation of findings. Compared with scoping reviews, realist synthesis goes beyond exploring and describing the evidence to explain mechanisms behind complex interventions using a method that is iterative, yet transparent. On the other hand, realist synthesis does not seek to appraise the evidence for effectiveness and produce a theoretical understanding of the literature as in systematic reviews, but rather engages stakeholders directly in the process to produce more pragmatic, implementable findings (see Table 1).

PFCC is a well-established and theoretically sound philosophy of care with a vast literature. Therefore, additional scoping and systematic reviews exploring and judging the effectiveness of PFCC are unlikely to lead to new and/or implementable findings (Kastner et al., 2011; Pawson et al., 2004; Wong et al., 2013). As an iterative, adaptable approach that includes multiple types of evidence and search strategies, realist synthesis is well equipped to deal with the complexity behind the aim of this research study, which is to understand and explain how, why, and under what circumstances PFCC is delivered in team-based geriatric home care. The Kastner et al. (2011) protocol for realist review was adopted to guide the five-step methodology described in the next sections, as it provided researchers with applied examples of each stage in the review process, which were adapted to the present study questions. The publication standards by Wong et al. (2013) guided the reporting requirements of the review for manuscript preparation.

\section{Step 1: Clarifying the Scope of the Review}

Realist synthesis starts with concept mining to develop an evaluative framework that will guide the search, assessment, and synthesis of evidence into a proposed theory to explain the outcomes of an intervention, the unique contexts in which they occur, and how these contexts influence the mechanism(s) that cause the outcomes (Astbury \& Leeuw, 2010; Kastner et al., 2011; Pawson et al., 2004; Rycroft-Malone et al., 2012; Wong et al., 2013). The key concepts of PFCC as defined by The Institute for Patient and Family-Centred Care (2010) were identified as a starting point for exploring team-based PFCC in geriatric home care. Then, a broad scoping review of core articles on PFCC was completed, using a pre-existing review on PFCC in home and community care as the main source of articles (Brookman et al., 2011). The preliminary evaluative framework that emerged proposed a conceptual understanding of team-based PFCC in geriatric home care based on apparent relationships between broad key concepts of PFCC and middle-range theories within the literature (Wong et al., 2013) (see Figure 1). All of the middle-range theories uncovered in the core article search were specific to only one of nursing, occupational therapy, and physiotherapy, and therefore, the remainder 
Table 1: The differences among three knowledge synthesis methods

\begin{tabular}{lccc}
\hline Knowledge Synthesis Approach & Scoping Review & Realist Synthesis & Systematic Review \\
\hline Goal & Explore & Explain & Appraise \\
Search strategy & Fluid & Iterative & Rigid \\
Quality assessment & Descriptive & Investigate/Test & Judgement \\
Implementation of findings & None & Pragmatic & Theoretical \\
\hline
\end{tabular}

of the review homed in on evidence within these three disciplines. No theories were uncovered during this core article search that explained how multiple disciplines could work together to implement PFCC, and none of the discipline-specific theories that were identified explicitly addressed the core concepts of Information Sharing and Collaboration as elaborated by the Institute for Patient and Family-Centred Care (2010).

Nursing contributions to PFCC appeared to align to the core concept of Dignity and Respect and could potentially be explained by the Human Becoming Theory (Bournes, 2002; Doucet \& Bournes, 2007; Legault \& Ferguson-Pare, 1999; Mitchell, Bournes, \& Hollett, 2006;
Parse, 1992), the Senses Framework (Nolan, Brown, Davies, Nolan, \& Keady, 2006; Nolan, Davies, Brown, Keaty, \& Nolan, 2004), and/or the Authentic Consciousness Theory (Gallant, Beaulieu, \& Carnevale, 2002; McCormack, 2003; McCormack, 2004). OT contributions to PFCC seemed to support the core concept of Participation and could potentially be explained by the Canadian Model of Occupational Performance (Doig, Fleming, Cornwell, \& Kuipers, 2009; Maitra \& Erway, 2006; Sumsion \& Law, 2006). Similarly, PT contributions to PFCC also seemed to be in line with the core concept of Participation and could potentially be explained by the International Classification of Functioning Disability and Health (Stucki, 2005). The lead

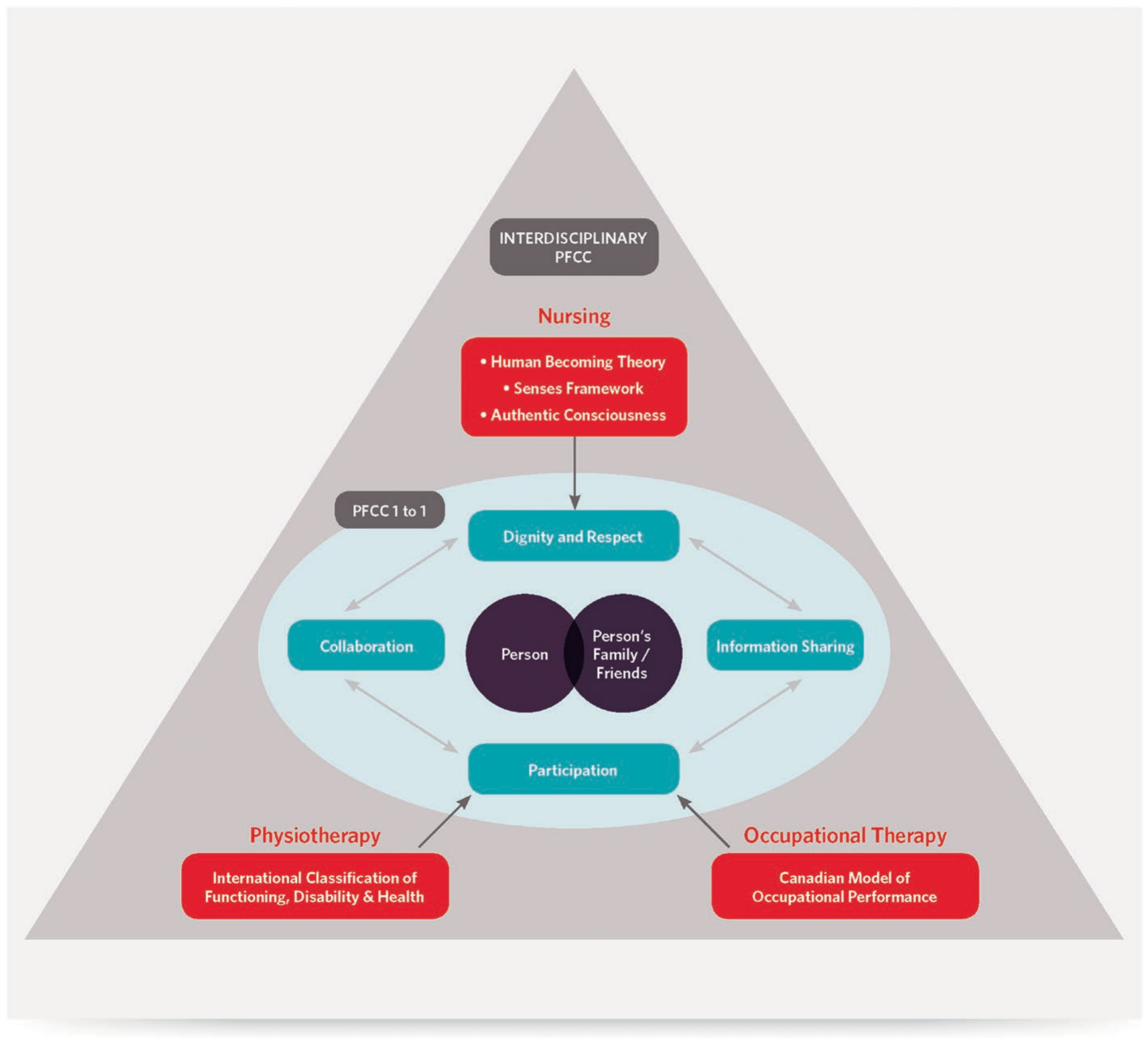

Figure 1: Preliminary evaluative framework guiding the search strategy and synthesis 
researcher (J.L.G.) met with the Geriatric Clinical Leadership Group $(n=14)$ of a large home and community care organization in Ontario to discuss and refine the preliminary evaluative framework.

\section{Step 2: Determining the Search Strategy}

The search for evidence was iterative and ongoing and involved multiple non-linear stages using a variety of sources. Following the core article search previously described, the next stage was expert-identified searching. Clinical experts in nursing $(n=8)$, OT $(n=2)$ and PT $(n=3)$ were consulted individually in informal interviews to gain insight into what articles, theories, and resources from their discipline should be included in the synthesis to understand how the core concepts of PFCC are achieved in a team-based geriatric home care setting (see Appendix A for interview guide). Starting with members of a National PFCC Advisory Committee within a large home and community care organization in Ontario and expert consultants from previous work conducted by the lead researcher (J.L.G.) in interdisciplinary geriatric home care, researchers used a snowball sampling strategy to identify and recruit these expert participants. Additional participants were recruited until saturation was reached, at which point no new resources, articles, or theories were emerging from the interviews (Atkinson \& Flint, 2004). The third stage involved a purposive search for published articles within the PubMed/MEDLINE ${ }^{\circledR}$ and Cumulative Index to Nursing and Allied Health Literature (CINAHL) databases. These databases were selected based on their likelihood of including evidence relevant to team-based PFCC involving nurses, OTs and PTs. A search strategy was developed in collaboration with a specialist librarian in the field of applied health sciences to explore the combined concepts of home care, PFCC, and teams (see Table 2). The search included articles in English published after 1990, as this was the earliest date of publication in the core article search phase, and the last date searched was June 10, 2015. The fourth stage of the search involved screening the reference lists of articles from stage three to identify any additional articles of relevance. The fifth stage of searching included a grey literature review of clinical practice guidelines related to PFCC by searching the Web sites of the regulatory bodies and associations for nursing, occupational therapy, and physiotherapy across Canada for PFCC and its many synonyms (see Table 2).

Table 2: Search strategy for step 3: Database searching

\begin{tabular}{|c|c|c|c|}
\hline Concepts & Home and Community Care & Person- and Family-Centred Care & Team-Based Care \\
\hline $\begin{array}{l}\text { Author keywords } \\
\text { [tiab] }\end{array}$ & $\begin{array}{l}\text { Home NOT Nursing Home } \\
\text { Communit* }\end{array}$ & $\begin{array}{l}\text { Person centred } \\
\text { Person centered } \\
\text { Patient centered } \\
\text { Patient centred } \\
\text { Client centred care } \\
\text { Client centered care } \\
\text { Consumer centered } \\
\text { Consumer centred } \\
\text { Relationship centred } \\
\text { Relationship centered } \\
\text { Family centered } \\
\text { Family centred } \\
\text { Person focused } \\
\text { Patient focused } \\
\text { Client focused } \\
\text { Consumer focused } \\
\text { Relationship focused } \\
\text { Patient directed } \\
\text { Person directed } \\
\text { Client directed } \\
\text { Consumer directed } \\
\text { Demand oriented }\end{array}$ & $\begin{array}{l}\text { Interprofessional } \\
\text { Interdisciplinary } \\
\text { Multidisciplinary team* }\end{array}$ \\
\hline $\begin{array}{l}\text { PubMed subject headings } \\
{[\mathrm{MeSH}]}\end{array}$ & $\begin{array}{l}\text { Community health services (noexp) } \\
\text { Home care services (exp) } \\
\text { Independent living }\end{array}$ & $\begin{array}{l}\text { Patient-centered care } \\
\text { Comprehensive health care (noexp) }\end{array}$ & Patient care team (noexp) \\
\hline CINAHL Subject headings & $\begin{array}{l}\text { Home health care+ } \\
\text { Community health services+ } \\
\text { Community living }\end{array}$ & $\begin{array}{l}\text { Patient centered care } \\
\text { Family centered care }\end{array}$ & Multidisciplinary care team \\
\hline
\end{tabular}




\section{Step 3: Article Selection and Quality Assessment}

A team of six researchers worked together to select and appraise articles in each phase of the review according to their relevance and rigour (Wong et al., 2013). In stage one of the search strategy, the titles and abstracts of 247 articles of interest, and subsequent full texts of 56 of these articles, were screened by the lead researcher (J.L.G.) and included if they defined the core concepts of PFCC, if they discussed PFCC in home and community care for older adults, and/or if they discussed theories for operationalizing PFCC. An additional two references were added to the core article search following consultation of the Geriatric Clinical Leadership Group. The broader research team reviewed the final list of 22 articles in this phase to confirm the selections made. Any discrepancies were discussed in a team meeting until consensus was reached.

In stage two of the search, the lead researcher (J.L.G.) developed an interview guide and corresponding Microsoft Excel spreadsheet tool to create a repository of references suggested for inclusion by the expert consultants (Microsoft, 2010). The interview guide and repository tool were reviewed by the broader research team and were refined based on their feedback. Two researchers (J.L.G. \& D.B.) each completed half of the expert interviews using the same interview guide and repository tool. Following the interviews, the two researchers (J.L.G. \& D.B.) met to debrief about the conversations and reach consensus on 42 suggested resources for inclusion based on their relevance to teambased PFCC in geriatric home care from the perspectives of nursing, occupational therapy, and physiotherapy.

Selection of articles in stage three of the search strategy involved three researchers (J.L.G., G.L. \& S.R.). The lead researcher (J.L.G.) led the development of inclusion/exclusion criteria for home care relevance, geriatric relevance, the involvement of nursing, occupational therapy and physiotherapy disciplines in team-based care, and the operationalization of one or more of the four concepts of PFCC (See Appendix B). A corresponding Microsoft Excel spreadsheet tool was developed to track the screening process (Microsoft, 2010). The inclusion/exclusion criteria and Excel tool were reviewed and refined with the other two researchers participating in this phase (G.L. \& S.R.). Both the title and abstract screening phase and subsequent full-text screening phase involved two of the three researchers (J.L.G., G.L., \& S.R.) individually reviewing the articles retrieved using the defined inclusion/exclusion criteria. Following their individual reviews, the two researchers met to compare their results and reach consensus on the list of articles that would move forward in the synthesis. In the full-text review stage, the Critical Appraisal Skills Program checklists for critical appraisal were added to the inclusion/exclusion criteria to ensure the final selection of articles had a clear purpose, included appropriate methods, cited relevant results, and asserted conclusions that were aligned with the review questions (Critical Appraisal Skills Program, 2013). Of the 1,226 references retrieved from the databases, 99 were moved forward to the data extraction phase.

The lead researcher (J.L.G.) led the bibliography screening in stage four of the search process. Articles were selected based on whether any of the keywords for PFCC and team-based care appeared in their titles (see Table 2). The researcher subsequently applied the inclusion/exclusion criteria from stage three to screen the full texts of these articles for inclusion in the synthesis. The addition of 13 articles to the synthesis from this phase was confirmed by the broader research team.

Stage five of the search strategy involved the lead researcher (J.L.G.) searching the Web sites of regulatory bodies and associations for nursing, occupational therapy, and physiotherapy in each province and territory in Canada, except Quebec, which was excluded because the Web sites were in French. The lead researcher (J.L.G.) used the search function within each Web site to search the keywords for PFCC (see Table 2) and find relevant guidelines and resources on PFCC within each discipline. A Microsoft Excel spreadsheet was developed to track these resources by province/territory and discipline (Microsoft, 2010). The final list of 30 grey literature references for inclusion was confirmed by the broader research team.

\section{Step 4: Extracting and Organizing the Data}

A customized data extraction tool using Microsoft Excel (Microsoft, 2010) was developed by the lead researcher (J.L.G.) to align with the key components and theories in the preliminary evaluative framework (see Appendix C). The goal was to identify data that explained how the key concepts of PFCC were operationalized within team-based geriatric home care. Emphasis was placed on extracting data that were relevant to the role of a particular discipline and/or all members of a geriatric home care team (context) and indicative of findings from pilot testing or randomized controlled trials of PFCC programs/interventions resulting in one or more of the four key concepts of PFCC (outcomes). Descriptions of the activities of PFCC programs and/or interventions and/or explanations and opinions about how and why PFCC works in these team-based settings to contribute to these particular outcomes were also captured (mechanisms). Data extraction for each reference included in the synthesis was completed by one of three researchers (J.L.G., G.L., \& S.R.) and consensus was either completed individually by another one of the three researchers (stage 3 ) or overall with the entire 
research team (stages 1, 2, 4, and 5). A further 47 articles were excluded at the data extraction phase for lack of detail describing the foregoing.

\section{Step 5: Synthesizing the Evidence and Drawing Conclusions}

Data synthesis was undertaken by the lead researcher (J.L.G.). Aligned with the realist synthesis method, a generative approach was used to explore theories of change for team-based PFCC interventions. The researcher analyzed outcomes $(\mathrm{O})$ resulting from various team-based PFCC activities by seeking to understand the mechanisms (M) that link them and the contexts $(\mathrm{C})$ in which these relationships form (Linsley, Howard, \& Owen, 2015). Extracted data from the five search phases were organized in chart format into context-mechanism-outcome configurations (CMOCs) to explain what, for whom, and in what circumstances team-based PFCC works (see Table 3) (Astbury \& Leeuw, 2010; Kastner et al., 2011). Thematic analysis was used to compare and contrast the CMOC data in order to test, refute, and fill out the proposed theories for explaining team-based PFCC in the evaluative framework. The final CMOCs were refined and named based on demi-regularities in the data to comprise the final proposed theory of team-based PFCC that was discussed and confirmed with the broader research team.

\section{Results}

\section{Search Outcomes}

Article selection, quality assessment, and data extraction for each of the search phases led to the inclusion of 159 references in the synthesis (see Figure 2).

\section{A Theoretical Framework for Describing Team-Based PFCC in Geriatric Home Care}

Five CMOCs under three themes came together as a theory to explain the contexts and underlying mechanisms for achieving PFCC outcomes in team-based geriatric home care, and how providers can individually and jointly contribute (see Figure 3).

\section{Theme 1: Dominant Contributions to PFCC by Individual Team Members at the Point-of-Care}

CMOC \#1: Relationship $(C) \rightarrow$ Understanding $(M) \longrightarrow$ Enabling Personhood (O)

Nursing contributions to PFCC are largely dependent on the context of their therapeutic relationships with patients and their families at home. In addition to being trained to intervene at the physiological level, nurses create a unique bond with patients and families through their ongoing focus on, and assessment of, psychosocial and emotional needs (Allen et al., 2004; McBride \& WaldenMcBride, 1995). This therapeutic nursing relationship is described as the core of nursing in the Therapeutic

Table 3. Sample context, mechanism, outcome data analysis table

\begin{tabular}{lcc}
\hline Context & Mechanism & Outcome \\
RELATIONSHIP & UNDERSTANDING & ENABLING PERSONHOOD
\end{tabular}

"We use APNs rather than social workers as care managers, since APNs are better trained to intervene at both the physiologic and psychosocial levels." (Allen et al., 2004)

"Nurse has a unique role to assess and promote the assessment of psychosocial elements of patient care; there is great importance in being able to enter a patient's role to understand what they are experiencing, feeling and believing" (McBride \& Walden- McBride, 1995)

"At the core of nursing is the therapeutic nurse-client relationship. The nurse establishes and maintains this key relationship by using nursing knowledge and skills, as well as applying caring attitudes and behaviours." (College of Nurses of Ontario, 2006)

"Establish a therapeutic relationship with the person using verbal and non-verbal communication strategies to build a genuine, trusting, and respectful partnership." (Registered Nurses Association of Ontario, 2015)
"The practice nurse uses the motivational interviewing tool 'Agenda setting' to raise issues considered important by the older person, the informal caregiver and the team. In agenda setting, rather than impose the professionals' priority on patients, one conducts an overview by inviting patients to select an issue or behaviour that they are most ready and able to tackle, feeling free also to express one's own views" (Daniels et al., 2007)

"P.I.E.C.E.S. ${ }^{\mathrm{TM}}$ is a best practice learning and development initiative that provides an approach to understanding and enhancing care for Individuals with complex physical and cognitive/mental health needs and behavioural changes. The P.I.E.C.E.S. ${ }^{\mathrm{TM}}$ model helps us to understand the whole person" (Alzheimer Society of Ontario, 2011)
"In the community matron competencies, the importance of community matrons empowering families, carers and others to support individuals with long term conditions and empowering individuals with long term conditions to represent their views and organize their own support, assistance or actions emphasized" (Masterson, 2007)

"The RN does not focus on adherence to medical regimens unless this is a participant-identified goal, which underscores the critical CAPABLE value that, engagement is more likely when participants are working on their own priorities." (Szanton et al., 2015)

Note. APN = advanced practice nurse; P.I.E.C.E.S. ${ }^{\mathrm{TM}}=$ Physical health, Intellectual abilities, Emotional wellbeing, Capabilities, Environment (social and physical) and his or her Social self; RN = registered nurse. 


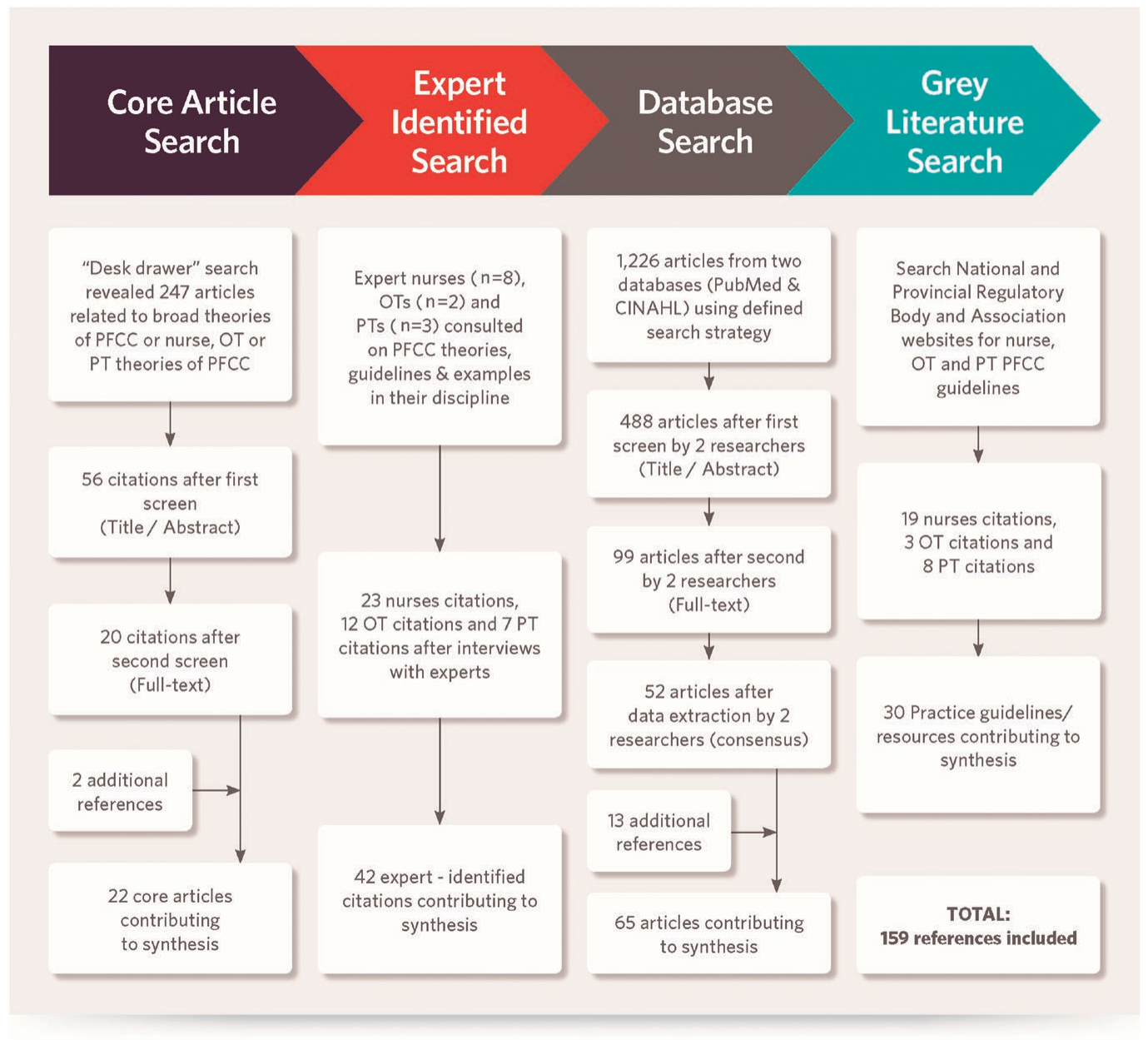

Figure 2: Flow diagram illustrating the search process

Nurse-Client Relationship Practice Standard (College of Nurses of Ontario, 2006) and is the hallmark of the first recommendation in the Nursing Best Practice Guidelines for Person and Family-Centred Care (Registered Nurses Association of Ontario, 2015). Nurses often act as care coordinators and managers within team-based care situations, as they are seen to be best situated to broker care with patients and families within the context of their relationship with them (Gerrity, 2005; Jones, Hepburn, Man, Ridout, \& Gable, 2011; Krumholz, et al., 2006; Lindsay, 2010; Stefanacci, 2013). Although the preliminary evaluative framework indicated that existing theoretical nursing contributions to PFCC were linked to the core concept of Dignity and Respect, data synthesis revealed that their contributions go beyond demonstrating dignity and respect in their care for patients, to actively enabling individual personhood to be influential in care planning and delivery for patients. This outcome was revealed in the literature through nurses empowering patients and families to represent their own views in care planning and decision making and ensuring that patients are working on their own priorities (Masterson, 2007; Szanton et al., 2015). Investigation into the mechanism that links the context of a relationship between nurses and patients and their families with enabling personhood in care revealed the importance of nurses uncovering and understanding the unique needs, preferences, and goals of individuals and their families. Examples of the mechanism of understanding operationalized in the data included motivational interviewing techniques to invite patients to set their own agenda for care (Daniels et al., 2011) and holistic assessment using the Physical health, Intellectual abilities, Emotional wellbeing, Capabilities, Environment (social and physical) and his or her Social self (P.I.E.C.E.S ${ }^{\mathrm{TM}}$.) model to understand how physical, intellectual, emotional, capability, environment, and social and cultural elements impact one's care (Alzheimer Society of Ontario, 2011).

The above-described CMOC and supporting evidence suggests strongly that the Human Becoming Theory (Bournes, 2002; Doucet \& Bournes, 2007; Legault \& Ferguson-Pare, 1999; Mitchell et al., 2006; Parse, 1992), the Senses Framework (Nolan et al., 2004; Nolan et al., 2006) and the Authentic Consciousness Theory (Gallant et al., 2002; McCormack, 2003; McCormack, 2004) are 


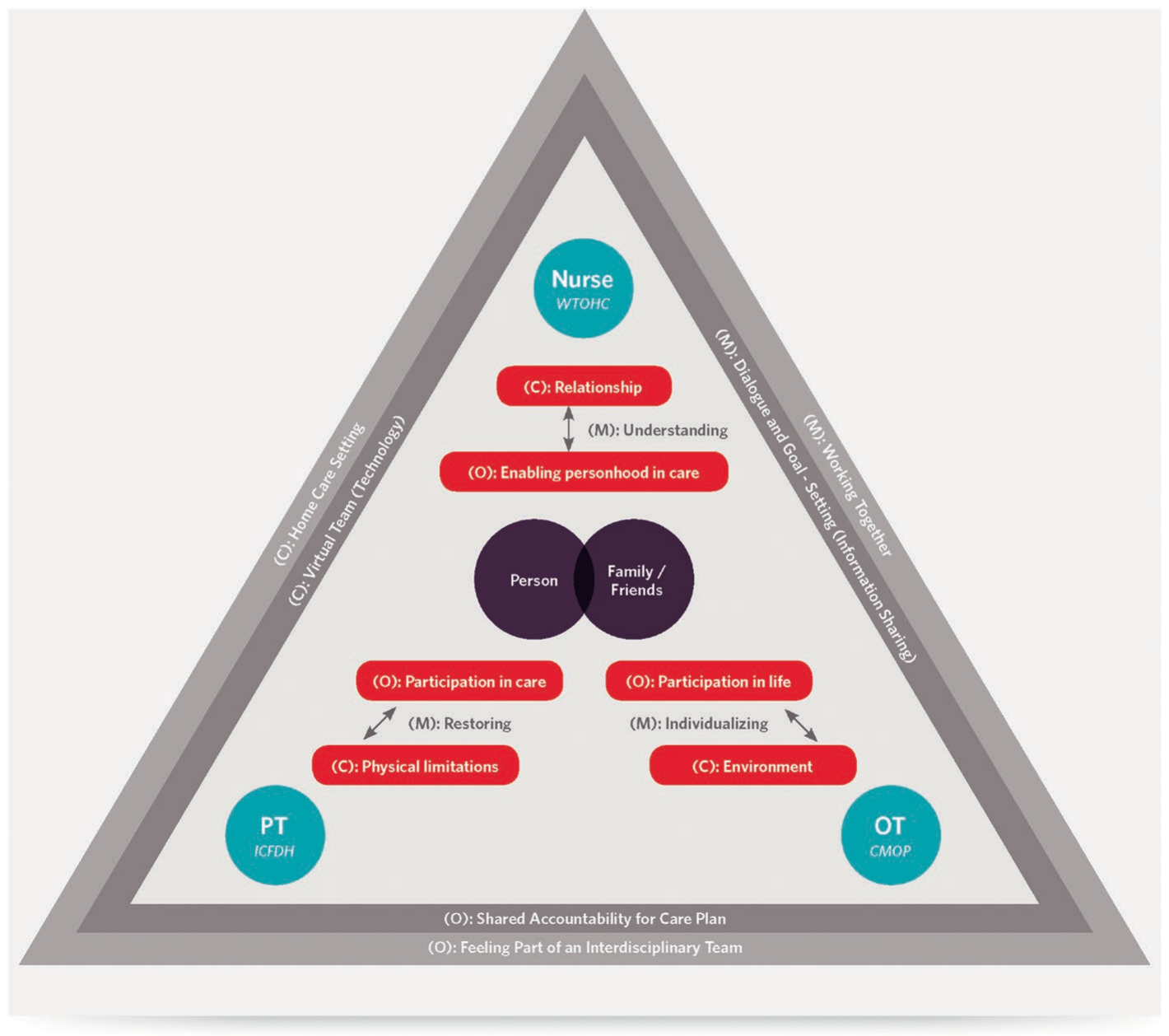

Figure 3: A theoretical framework for describing team-based PFCC in geriatric home care

not the most appropriate theories for explaining nursing contributions to PFCC at the point-of-care in geriatric home care. Instead, Watson's Theory of Human Caring emerged as a more suitable theory for explaining the nursing role in PFCC. Watson's Theory of Human Caring is a relational theory of care that aims to "protect, enhance, promote, and potentiate human dignity, wholeness, and healing, wherein a person creates or co-creates his or her own meaning for existence, healing, wholeness, and living and dying" (Watson \& Woodward, 2010, p. 327). This outcome is achieved through caring moments, which are intentional, authentic, and meaningful interactions that honour the person and centre on shared human experience (Watson Caring Science Institute, 2010).

\section{CMOC \#2: Environment $(C) \longrightarrow$ Individualizing $(M) \longrightarrow$ Participation in Life (O)}

The context of an individual's physical, institutional, cultural, and social environment emerged from the data as the basis for OT contributions to team-based PFCC at the point-of-care in geriatric home care (Vik, Lilja, \& Nygard, 2007). OTs actively assess individuals performing daily activities within the full scope of their environment rather than just focusing on the physical environment in isolation (Comunale, 1992; Szanton et al., 2015). For example, in the Stroke Rehabilitation Enhancing and Guiding Transition Home (STRENGTH) program for stroke rehabilitation, an OT completes home visits with the patient prior to the patient's discharge from hospital to ensure they are able to assess the full range of the patient's environment (Gustafsson, Fleming, Cornwell, Worrall, \& Brauer, 2014). The idea that occupational therapy is linked to the PFCC core concept of Participation in the preliminary evaluative framework was confirmed by the data; however, it became clear that OTs specifically focus on the outcome of patient participation within the context of the patient's day-to-day life activities (occupations) in addition to providing care. For example, in a community dementia services program, the goal for OTs is not to promote independence in task performance within patients' care plans, but rather to help people to achieve the lifestyle that they choose, through adapted support (Gladman et al., 2007). In a community rehabilitation program for persons with traumatic brain injury, OTs develop client individualized program plans (CLIPPs) to help the care team link the 
short-term rehabilitation care goals to the clients' longterm lifestyle goals (Letts \& Dunal, 1995). According to the data, the mechanism that explains how an OT achieves patient participation in life activities through the lens of an individual's environment is through individualization of adaptive approaches based on someone's cognitive, affective, physical, and spiritual self. In a home-based program for older adults with arthritis, the OT constantly "analyzes the fit between the person, the device/strategy and environmental factors in order to optimize performance" in their activities (Pizzimenti \& Roberts, 2005, p. 9). In terms of individualizing adaptive strategies, OTs can use photographs, memorabilia of life events, and other objects that have meaning to people in their homes to help connect and engage patients in their care plans (Comunale, 1992). The description of the OT role in a disability prevention program for community-dwelling seniors provides further support for the individualization mechanism: “...identifies the activities meaningful to this person, the problems or concerns the older person expressed in performing activities, and the risk factors for developing disabilities. This is followed by analyses in which concepts as personal causation (including self-efficacy), values, interests, roles, habits, performance capacity (mental and physical functions), skills (motor, cognitive, communicative), and the physical and social environment are taken into account." (Daniels et al., 2011, p. 969).

These data confirm that the Canadian Model of Occupational Performance provides the best theoretical explanation of an OT's individual contributions to teambased PFCC, as it illustrates the dynamic relationship between the person and the person's environment and occupations (Canadian Association of Occupational Therapists, 2015; Doig et al., 2009; Egan, Dubouloz, Von Zweck, \& Vallerand, 1998; Enemark Larson \& Carlsson, 2012; Maitra \& Erway, 2006; Prince Edward Island Occupational Therapy Society, n.d.; Sumsion \& Law, 2006; Townsend \& Polatajko, 2007).

\section{CMOC \#3: Physical Limitations $(C) \rightarrow$ Restoring $(M) \rightarrow$ Participation in Care $(O)$}

PTs contribute to team-based PFCC at the point of care within the context of an individual's physical limitations. Evidence of this context emerged from the approach to PT documentation called "subjective, objective, assessment, and plan (SOAP) notes," which include subjective, objective, and assessment information about an individual's condition or limitation and a plan for treatment (Mangusan, 2014). PTs have a detailed understanding of how the body works; knowledge of disease, injury, and healing; and the ability to detect abnormal posture, balance, and movement (Nova Scotia Physiotherapy Association, 2015). Similar to the analysis of the OT perspective, the data confirmed the idea that
PTs' contributions to team-based PFCC are related to the core concept of Participation; however, it became clear that the role PTs play is to specifically achieve the outcome of patient and family participation in care activities. The movement continuum theory of physical therapy supports this outcome, indicating that a PT's role is to minimize, through active therapy focusing on the whole body and/or body parts, the differential between an individual's preferred movement capacity and that person's current movement capacity (Cott \& Finch, 2007; Cott et al., 1995). PTs are able to "offer more than baseline function assessments and prescribed exercise programs. They are vital in reinforcing the activities that patients can perform" (Comunale, 1992, p. 14). The mechanism that links the context of physical limitations with the outcome of participation in care activities was revealed to be that physiotherapists' work to restore patients' individual function (Ryburn, Wells, \& Foreman, 2009). This restoring mechanism is evident in the goals for the expansion of person-centred physiotherapy services in Ontario (Ontario Association of Community Care Access Centres, 2014). Physiotherapy is described in Canada as "anchored in movement sciences and aims to enhance or restore function of multiple body systems" (Canadian Physiotherapy Association, 2012, p. 2). A restorative home care program provided an example of the above-described CMOC for PT PFCC, stressing the importance of assessing impairments that impede function including mental status, depression, and gait and balance deficits in order to encourage patients to participate in their self-care activities (Baker, Gottschalk, Eng, Weber, \& Tinetti, 2001). The International Classification of Functioning Disability and Health was confirmed as the theory that best explains the PT role in team-based PFCC at the point of care, as it links body structures and impairments with activities and participation through restoring function using both personal and environmental factors (Finger, Cieza, Stoll, Stucki, \& Huber, 2006; Stucki, 2005; World Health Organization, 2001).

\section{Theme 2: Team Functions in Achieving PFCC}

CMOC \#4: Virtual Team (Technology) $(C) \rightarrow$ Dialogue and Goal Setting (Information sharing) $(M) \rightarrow$ Shared Accountability for Care Plan (O)

When they are working in the context of an interdisciplinary team, it seems reasonable that people from each discipline could share their individual skills, knowledge, and contributions to PFCC, and be willing to learn about each other's areas of expertise so as to complement and support each other in their PFCC roles (Clancy, 2015; Phillips et al., 2001). This idea of different, yet coordinated, contributions to PFCC was buttressed from the finding in the data synthesis that Communication is a key function of PFCC within teambased geriatric home care, which expands the current 
Information Sharing key concept of PFCC. As home care is an environment where providers work largely in isolation from each other, the context of a virtual team, established through technology, emerged from the data as being essential to team-based PFCC. In a review of multiprofessional communication in caring for older people during transitions, communication pathways that involved information technology systems or information transfer were found to be critical in all 10 of the reviewed studies (Allen, Ottmann, \& Roberts, 2011). The value of health information technology in promoting virtual teamwork was described by Cipriano et al. (2013): "HIT [Health information technology] can facilitate efficient and successful care coordination by linking patients and providers with data and information... HIT makes possible... multidirectional communication among patients and providers and the greater health care community (p. 467)." Information sharing portals, electronic health records, and telehealth applications to monitor patients in their homes are further examples from the literature of home health care within the context of a virtual team environment through technology (Joseph, 2014; Nandram \& Koster, 2014; Radhakrishnan, Xie, \& Jacelon, 2016).

Successful communication within the context of a virtual team results in person-centred rather than professional-centred care plans and shared accountability for care planning and delivery (Masterson, 2007; Cipriano et al., 2013). The literature showed that teams achieved this outcome by establishing common patient-centred goals, fostering collective ownership of common goals, and giving all team members the opportunity to contribute to a comprehensive clinical picture of a patient (Edes et al., 2014; Hirth, Baskins, \& Dever-Bumba, 2009; Oxtoby \& Eikaas, 1993). Inherent in these outcomes is the mechanism of dialogue and goal setting among team members, including patients and families. Dialogue requires interaction and negotiation among team members, beyond passive information sharing (Allen et al., 2011). Goal setting through comprehensive assessment can help to foster that collaborative interaction: Comprehensive assessment can "create a safe environment to encourage thinking and communicating about emotionally intense issues" (McSkimming, London, Lieberman, Quinn, \& Carney, 2004, p. 170). This knowledge synthesis did not reveal any existing theories to support this CMOC explaining the team function of communication.

\section{Theme 3: System Level Needs for Achieving Team-Based PFCC}

CMOC \#5: Home Care Setting $(C) \rightarrow$ Working Together $(M) \rightarrow$ Feeling Part of an Interdisciplinary Team (O) A subset of references included in the realist synthesis homed in on the need for enhanced interprofessional education to support point-of-care PFCC delivery within a team. Specifically, interprofessional education within the context of the home care setting is important as most interprofessional education to date is situated in classrooms or institutional/clinical care settings (Fitzpatrick, 1998). Examples in the literature of interprofessional education within the home care context include students from multiple disciplines listening to and learning from providers, patients, and families in their homes; shadowing interdisciplinary home care teams; and creating authentic virtual representations of the home care environment for use in classroom learning situations (Anderson \& Lennox, 2009; Founger \& Horntvedt, 2011; Sabus, Sabata, \& Antonacci, 2011). The goal for interprofessional education to support team-based PFCC in geriatric home care is to promote the feeling of connectedness as part of an interdisciplinary team. A panel on interdisciplinary education held by the National League for Nursing indicated: "cooperation and collaboration should be woven throughout every aspect of the curriculum and built into every learning experience...Clinical competence is necessary for trust and respect, and it is probably the most important basis for successful collaborative relationships among providers." (Fitzpatrick, 1998, p. 63).

Students who took part in the Leicester Model of interprofessional education in community settings in the United Kingdom indicated that an awareness of patientcentred teamwork through sharing different professional perspectives enhanced both their skills and their appreciation for teamwork (Anderson \& Lennox, 2009). The mechanism that was uncovered to support the outcome of feeling part of a team within the context of home care is providing interdisciplinary groups of students the opportunity to work together to apply PFCC in real-time care planning. For example, in the Seamless Care model of interprofessional education, students are responsible for facilitating a patient transition home from the hospital and have to work together to develop teamwork skills while actively planning real patient care (Mann et al., 2009). No existing theory was uncovered in this knowledge synthesis to explain the above-described CMOC around system level support for team-based PFCC; however, this CMOC is somewhat relevant to the Institute for Patient and FamilyCentred Care (2010) key concept of Collaboration, as patients and providers working together in the implementation of professional education can help to link theory and practice (Cooper \& Spencer-Dawe, 2006).

\section{Discussion}

\section{Summary of Main Findings}

The proposed theory of team-based PFCC in geriatric home care emerging from this realist synthesis involves both the individual contributions of providers from 
unique disciplines and their collective contributions through communication in the context of a virtual team. Individually, these distinct contributions to PFCC could be viewed as a barrier to achieving team-based PFCC, because each discipline may only narrowly focus on the element of PFCC that their discipline highlights as important. However, this synthesis and proposed theory indicate that these differences could be a strength when combined, in that a team can rely on the unique contributions of each of its members through the virtual team function of communication to ensure a comprehensive and tailored delivery of PFCC. According to the proposed theory, achieving teamwork in PFCC also requires system level support in the form of interprofessional education that provides students from different disciplines the opportunity to learn and trial team-based PFCC in their training in order to embed the philosophy of PFCC in their eventual practice.

This knowledge synthesis revealed some weaknesses in the existing key concepts of PFCC defined by the Institute for Patient and Family-Centred Care (2010), when viewing PFCC from a team-based perspective. For example, although Dignity and Respect emerged as being particularly aligned to nursing contributions to PFCC, the data indicated that dignity and respect in nursing within the context of team-based geriatric home care goes beyond treating people with kindness and cultural sensitivity, to actively enabling and advocating for their personhood to be represented in care. Similarly, the key concept of Participation was aligned with both occupational therapy and physiotherapy contributions to PFCC, but the data helped to illuminate important differences between the participation on which these two disciplines focus in a team setting. The proposed theory of team-based PFCC revealed Communication as being the central team function of PFCC, which includes the Institute for Patient and Family-Centred Care (2010) key concept of Information Sharing, but emphasizes dialogue and discussion. Collaboration as defined by the Institute for Patient and Family-Centred Care (2010) was not supported in this study at the point of care; however, it was learned that the interprofessional learning process for home care should involve clients, families, providers, and students working together.

\section{Limitations}

The decision to focus the realist synthesis explicitly on the disciplines of nursing, occupational therapy, and physiotherapy may limit the generalizability of the emergent theory of team-based PFCC in geriatric home care, as the majority of home care services, particularly in Canada, are delivered by unregulated providers (Human Resources Development Canada, 2003). However, a recent scoping review revealed that the role of unregulated providers is poorly defined, categorized, and underappreciated in current Canadian health care and health care literature (Afzal, Stolee, Heckman, Boscart, \& Sanyal, 2018), and so their explicit inclusion in this review would have been unlikely to reveal substantive additional contexts and mechanisms underlying the delivery of team-based PFCC. Although the individual contributions to PFCC of unregulated providers and other professional disciplines were not actively explored in this review, many different types of providers were represented in the teams within the discipline-specific literature reviewed, and, therefore, it is believed that the team function of communication for PFCC in geriatric home care is relevant to all types of providers. Further, as unregulated providers are typically supervised by one of the three disciplines included in this review (Local Health Integration Networks, 2014), their individual participation in team-based care is likely inherent to the CMOCs represented in the theory.

Another limitation of this study is that the grey literature review included clinical practice guidelines from Canada only; although strategies for team-based PFCC from other countries were captured in the database review and helped to develop the proposed theory. Lastly, this research focused on teamwork in geriatric home care and did not explore other sectors and populations in which team-based PFCC might be applied. However, it is believed that the CMOCs in the proposed theory may be generalizable to other situations of team-based PFCC, although the specific activities to operationalize the mechanisms might be different.

\section{Next Steps}

The proposed theory of team-based PFCC in geriatric home care is relevant to a variety of stakeholders in geriatric home care including researchers, health care organizations, point-of-care providers, and policy makers. The theory could be used to explore alternative definitions and key concepts of PFCC, to ensure they are more reflective of the reality of team-based care. For example, the Health Foundation principles of PFCC include Enabling as a key concept, which is well aligned to the unique contributions of nurses, OTs, and PTs uncovered in this study (The Health Foundation, 2015). Additional research is needed to explore alternative broad conceptualizations of PFCC and their alignment to the proposed theory for team-based PFCC. Although education and resources exist to guide the provision of PFCC more broadly (Saint Elizabeth Health Care, 2015b), health care organizations could apply this theory in the development of new or refined education, resources, and tools to guide point-of-care teams in their delivery of team-based PFCC in geriatric home care and beyond. The proposed theory for teambased PFCC could also inform novel team-based PFCC interventions aimed at improving the PFCC experience 
of older adults and their family/friend caregivers. The four key concepts of PFCC as defined by the Institute for Patient and Family-Centred Care (2010) that were further elaborated on in this review could also serve to clarify important outcomes for measurement and evaluation of PFCC initiatives in the future. Future research could also explore the applicability of the emergent program theory to the role of unregulated providers in geriatric home care. Finally, this theory could guide policy makers in decisions about service and resource allocation in geriatric home care, to ensure that all older adults receive comprehensive PFCC care. For example, given the different roles they play in PFCC, individuals may require care from both OTs and PTs depending on their goals for participation; however, services from both types of providers are not always currently available (Cott, Falter, Gignac, \& Badley, 2008).

\section{Conclusion}

This realist synthesis has resulted in a theory that posits that team-based PFCC in geriatric home care requires the unique individual contributions of nurses, OTs, and PTs, in addition to the team-based PFCC function of communication and system level support through education. If a geriatric home care team is not composed of people from these three disciplines, there would appear to be a need to compensate for the absence of the missing discipline's strength in the delivery of PFCC to complement the other disciplines' contributions. Because of gaps in understanding how to work together, geriatric home care teams must find ways to capitalize on and combine the predominant contributions of different providers in the delivery of PFCC while supporting virtual teamwork to ensure that personhood, function, and life activities are equally represented foci in the delivery of care.

\section{References}

Adams, J., \& Drake, R. (2006). Shared decision-making and evidence-based practice. Community Mental Health Journal, 42(1), 87-105.

Afzal, A., Stolee, P., Heckman, G., Boscart, V., \& Sanyal, C. (2018). The role of unregulated care providers in Canada-A scoping review. International Journal of Older People Nursing, 13(3), e12190.

Allen, K., Hazelett, S., Jarjoura, D., Wright, K., Clough, L., \& Weinhardt, J. (2004). Improving stroke outcomes: Implementation of a postdischarge care management model. Journal of Clinical Outcomes Management, 11(11), 707-714.

Allen, J., Ottmann, G., \& Roberts, G. (2011). Multi-professional communication for older people in transitional care: A review of the literature. International Journal of Older People Nursing, 8, 253-269.
Alzheimer Society of Ontario. (2011). About P.I.E.C.E.S Retrieved from http://u-first.ca/u-first-curriculum/ about-p-i-e-c-e-s /

Anderson, E., \& Lennox, A. (2009). The Leicester model of interprofessional education: Developing, delivering and learning from student voices for 10 years. Journal of Interprofessional Care, 23(6), 557-573.

Astbury, B., \& Leeuw, F. L. (2010). Unpacking black boxes: Mechanisms and theory building in evaluation. American Journal of Evaluation, 31(3), 363-381.

Atkinson, R., \& Flint, J. (2004). Snowball sampling. In M.S. Lewis-Beck, A. Bryman, \& T. Futing Liao (Eds.), The SAGE encyclopedia of social science research methods (pp. 10441045). Thousand Oaks, CA: SAGE Publications, Inc. doi: http:/ / dxdoi.org/10.4135/9781412950589.n931

Baker, D. I., Gottschalk, M., Eng, C., Weber, S., \& Tinetti, M. E. (2001). The design and implementation of a restorative care model for home care. The Gerontologist, 41(2), 257-263.

Ball, T. (2010). Disruptive innovation: Patient/family-focused care. Managing Change, 90(3), 421-456.

Beech, R., Ong, B. N., Jones, S., Edwards, V. (2017). Delivering person-centred holistic care for older people. Quality in Ageing and Older Adults, 18(2) 157-167.

Bender, D., \& Holyoke, P. (2016). Bringing person-and familycentred care alive in home, community and long-term care organizations. Healthcare Quarterly; 19(1):70-75.

Bournes, D. A. (2002). Research evaluating human becoming in practice. Nursing Science Quarterly, 15(3): 190-195.

Brookman, C., Jakob, L., DeCicco, J., \& Bender, D. (September 2011). Client-centred care in the Canadian home and community sector: A review of key concepts. Retrieved from https:/ / www.saintelizabeth.com/getmedia/4aba6e8e0303-4b9c-9117-a8c22a43f8bd/Client-Centred-Carein-the-Canadian-Home-and-Community-Sector.pdf. aspx

Canadian Association of Occupational Therapists. (2015). Canadian model of occupational performance. Retrieved from: http:/ / www.caot.ca / default.asp?pageid=3781

Canadian Physiotherapy Association. (2012). Description of physiotherapy in Canada. Retrieved from http:/ / www. physiotherapy.ca/getmedia / e3f53048-d8e0-416b-9c9d38277c0e6643/DoPEN(final).pdf.aspx

Change Foundation, The. (February 2011). Because this is the rainy day: A discussion paper on home care and informal caregiving for seniors with chronic health conditions. Retrieved from https://www.changefoundation.ca/ because-this-is-the-rainy-day/

Cipriano, P. F., Bowles, K., Dailey, M., Dykes, P., Lamb, G., \& Naylor, M. (2013). The importance of health information technology in care coordination and transitional care. Nursing Outlook, 61, 475-489. 
Clancy, A. (2015). Practice model for a dementia outreach service in rural Australia. The Australian Journal of Rural Health, 23(2), 87-94.

Coleman, E. A. (2003). Falling through the cracks: Challenges and opportunities for improving transitional care for persons with continuous complex care needs. Journal of the American Geriatrics Society, 51, 549-555.

Coleman, E. A., \& Boult, C. (2003). Improving the quality of transitional care for persons with complex care needs. Journal of the American Geriatrics Society, 51(4), 556-557.

College of Nurses of Ontario. (June 2006). Practice standard: Therapeutic nurse-client relationship. Retrieved from https://www.cno.org/Global/docs/prac/41033_ Therapeutic.pdf

Comunale, D. L. (1992). Collaborative care planning with the arthritic client at home. Journal of Home Health Care Practice, $4(2), 8-15$.

Cooper, H., \& Spencer-Dawe, E. (2006). Involving service users in interprofessional education narrowing the gap between theory and practice. Journal of Interprofessional Care, 20(6), 603-617.

Cott, C. A. (2004). Client-centred rehabilitation: Client perspectives. Disability and Rehabilitation, 26(24), 1411-1422.

Cott, C. A., Boyle, J., Fay, J., Sutton, D., Bowring, J., \& Lineker, K. (2001). Client centred rehabilitation. A report to the Ontario Ministry of Health and Long-Term Care. Arthritis Community Research \& Evaluation Unit (ACREU). Retrieved from http:/ /www.acreu.ca/pdf/pub5/01-03.pdf .

Cott, C. A., Falter, L. B., Gignac, M., \& Badley, E. (2008). Helping networks in community home care for the elderly: Types of team. Canadian Journal of Nursing Research, 40(1), 19-37.

Cott, C. A., \& Finch, E. (2007). Invited commentary on the movement continuum special series. Physical Therapy, 87(7), 925-926.

Cott, C. A., Finch, E., Gasner, D., Yoshida, K., Thomas, S. G., \& Verrier, M.C. (1995). The movement continuum theory of physical therapy. Physiotherapy Canada, 47(2), 87-95.

Cott, C. A., Wiles, R., \& Devitt, R. (2007). Continuity, transition and participation: Preparing clients for life in the community post-stroke. Disability and Rehabilitation, 29(20-21), 1566-1574.

Covinsky, K. E., Palmer, R. M., \& Fortinsky, R. H. (2003). Loss of independence in activities of daily living in older adults hospitalized with medical illnesses: Increased vulnerability with age. Journal of American Geriatrics Society, 51, 451-458.

Critical Appraisal Skills Program. (2013). CASP checklists. Retrieved from http:/ / www.casp-uk.net/\#!casp-toolschecklists / c18f8

Daniels, R., van Rossum, E., Metzelthin, S., Sipers, W., Habets, H., Hobma, S., et al. (2011). A disability prevention programme for community-dwelling frail older persons. Clinical Rehabilitation, 25(11), 963-974. de Haes, H. (2006). Dilemmas in patient centeredness and shared decision making: A case for vulnerability. Patient Education and Counseling, 62(3), 291-298.

Department of Health and Human Services. (2006). What is person-centred health care? A literature review. Retrieved from https://www2.health.vic.gov.au/ getfile/?sc_itemid=\%7BCC68AD22-6F31-42BE-87FA287ACB0335FF\%7D\&title $=$ What $\% 20$ is $\% 20$ personcentred $\% 20$ health $\% 20$ care $\% 3 \mathrm{~F} \% 20 \mathrm{~A} \% 20$ literature $\% 20$ review $\% 20$

DiLollo, A., \& Favreau, C. (2010). Person-centered care and speech and language therapy. Seminars in Speech $\mathcal{E}$ Language, 31(2), 90-97.

Doig, E., Fleming, J., Cornwell, P. L., \& Kuipers, P. (2009). Qualitative exploration of a client-centered, goal-directed approach to community-based occupational therapy for adults with traumatic brain injury. American Journal of Occupational Therapy, 63(5), 559-568.

Doucet, T. J., \& Bournes, D. A. (2007). Review of research related to Parse's Theory of Human Becoming. Nursing Science Quarterly, 20(1), 16-32.

Dow, B., Haralambous, B., Bremner, F., \& Fearn, M. (2006). What is person-centred health care: A literature review. Melbourne, Victoria, Australia: National Ageing Research Institute.

Edes, T., Kinosian, B., Vuckovic, N.H., Nicholas, L.O., Becker, M.M., \& Hossain, M. (2014). Better access, quality, and cost for clinically complex veterans with home-based primary care. The Journal of the American Geriatrics Society, 62, 1954-1961.

Edvardsson, D., \& Innes, A. (2010). Measuring personcentered care: A critical comparative review of published tools. The Gerontologist, 50(6), 834.

Edvardsson, D., Winblad, B., \& Sandman, B. (2008). Person-centred care of people with severe Alzheimer's disease: Current status and ways forward. The Lancet, 7, 362-367.

Egan, M., Dubouloz, C.- J., Von Zweck, C., \& Vallerand, J. (1998). The client-centred evidence-based practice of occupational therapy. Canadian Journal of Occupational Therapy, 5(3), 136-143.

Enemark Larsen, A., \& Carlsson, G. (2012). Utility of the Canadian Occupational Performance Measure as an admission and outcome measure in interdisciplinary community-based geriatric rehabilitation. Scandinavian Journal of Occupational Therapy, 19(2), 204-213.

Epstein, M. D. \& Street, R. L. (2011). The values and value of patient-centred care. Annals of Family Medicine 9(2), 100-103.

Expert Group on Home and Community Care. (2015). Bringing Care Home. Toronto: Government of Ontario. Retrieved from http://health.gov.on.ca/en/public/programs / lhin/docs/hcc_report.pdf 
Finger, M. E., Cieza, A., Stoll, J., Stucki, G., \& Huber, E. O. (2006). Identification of intervention categories for physical therapy, based on the international classification of functioning, disability and health: A delphi exercise. Physical Therapy, 86(9), 1203-1220.

Fitzpatrick, J. J. (1998). Building community: Developing skills for interprofessional health professions education and relationship-centered care. Interdisciplinary Health Education Panel of the National League for Nursing. Journal of Nursing Midwifery, 19(2), 86-90.

Founger, M., \& Horntvedt, T. (2011). Students' reflections on shadowing interprofessional teamwork: A Norwegian case study. Journal of Interprofessional Care, 25, 33-38.

Gallant, M. H., Beaulieu, M. C., \& Carnevale, F. A. (2002). Partnership: An analysis of the concept within the nurse-client relationship. Journal of Advanced Nursing, 40(2), 149-157.

Gerrity, E. P. (2005). Care management and wound care: The expanding role of the care manager in the new millennium and opportunities for collaboration and innovation. Home Health Care Management $\mathcal{E}$ Practice, 17(3), 175-182.

Gladman, J. R., Jones, R. G., Radford, K., Walker, E., \& Rothera, I. (2007). Person-centred dementia services are feasible, but can they be sustained? Age and Ageing, 36(2), 171-176.

Gustafsson, L., Fleming, J., Cornwell, P., Worrall, L., \& Brauer, S. (2014). STRENGTH and the health care team: Changing interprofessional and client-centered practices. Topics in Stroke Rehabilitation, 21(5), 413-420.

Gustafsson, S., Lood, Q., Wilhelmson, K., HaggblomKronlof, G., Landahl, S., \& Dahlin-Ivanoff, S. (2015). A person-centred approach to health promotion for persons 70+ who have migrated to Sweden: Promoting aging migrants' capabilities implementation and RCT study protocol. BMC Geriatrics, 15, 10.

Health Foundation, The. (2015). Person-centred care resource centre. Retrieved from http:/ / personcentredcare.health. org.uk/area-of-care/principles-of-person-centred-care

Hewitt, G., Sims, S., Greenwood, N., Jones, F., Ross, F., \& Harris, R. (2015). Interprofessional teamwork in stroke care: Is it visible or important to patients and carers? Journal of Interprofessional Care, 29(4), 331-339.

Hewitt, G., Sims, S., \& Harris, R. (2014). Using realist synthesis to understand the mechanism of interprofessional teamwork in health and social care. Journal of Interprofessional Care, 28(6), 501-506.

Hirth, V., Baskins, J., \& Dever-Bumba, M. (2009). Program of all-inclusive care (PACE): Past, present, and future. Journal of the American Medical Directors Association, 10, 155-160.

Hobbs, J. L. (2009). A dimensional analysis of patient-centered care. Nursing Research, 58(1), 52-62.
Holland-Bloorview Kids Rehabilitation Hospital. (2013). Mission, vision and values. Retrieved from http:// hollandbloorview.ca / aboutus / welcometohollandbloorview / mission, \%20vision\%20and\%20values

Human Resources Development Canada. (2003). Canadian Home Care Resources Study, 2002 Synthesis Report. Retrieved from www.homecarestudy.ca/en/news/ docs/EngSynth.pdf

Institute for Patient and Family Centred Care (October 29, 2010). Frequently asked questions. Retrieved from http:// www.ipfcc.org/faq.html

Johnson, B., Abraham, M., Conway, J., Simmons, L., EdgmanLevitan, S., Sodomka, P., et al. (2008). Partnering with patients and families to design a patient- and family-centered health care system: Recommendations and promising practices. Bethesda, MD: Institute for Family-Centered Care and the Institute for Healthcare Improvement.

Jones, M., Hepburn, S., Man, J., Ridout, J., \& Gable, D. (2011). A community outreach service for vulnerable people with diabetes. Diabetes \& Primary Care, 13(2), 111.

Joseph, F. (2014). Just do it, 'cos I've got your back!' Diabetes care: The West Cheshire Way. Practical Diabetes, 31(4), 169-172a.

Kane, P.M., Murtagh, F.E., Ryan, K., Mahon, N.G.,McAdam, B., McQuillan, R., et al. (2015). The gap between policy and practice: A systematic review of patient-centred care interventions in chronic heart failure. Heart Failure Reviews, 20(6): 673-687.

Kastner, M., Estey, E., Perrier, L., Graham, I. D., Grimshaw, J., Straus, S. E., et al. (2011). Understanding the relationship between the perceived characteristics of clinical practice guidelines and their uptake: Protocol for a realist review. Implementation Science, 6, 69.

Kitson, A., Marshall, A., Bassett, K., Zeitz, K. (2013). What are the core elements of patient-centred care? A narrative review and synthesis of the literature from health policy, medicine and nursing. Journal of Advanced Nursing, 69(1), 4-15.

Krumholz, H. M., Currie, P. M., Riegel, B., Phillips, C. O., Peterson, E. D., Smith, R., et al. (2006). A taxonomy for disease management: A scientific statement from the American Heart Association Disease Management Taxonomy Writing Group. Circulation, 114(13), 1432-1445.

Legault, F., \& Ferguson-Pare, M. (1999). Advancing nursing practice: An evaluation study of Parse's theory of human becoming. Canadian Journal of Nursing Leadership, 12(1), 30-35.

Letts, L., \& Dunal, L. (1995). Tackling evaluation: Applying a programme logic model to community rehabilitation for adults with brain injury. Canadian Journal of Occupational Therapy, 62(5), 268-277.

Lindsay, S. (2010). Collaborative model for end-stage dementia care. Mental Health Practice, 13(7), 18-22. 
Linsley, P., Howard, D., \& Owen, S. (2015). The construction of context-mechanisms-outcomes in realistic evaluation. Nurse Researcher, 22(3), 28-34.

Local health Integration Networks. (2014). Personal support and homemaking services schedule. Local Health Integration Networks. Retrieved from http:/ / healthcareathome.ca/serviceproviders/en/Documents/ Schedule_3_-_Personal_Support_and_Homemaking Services_Schedule_(Consolidated_Services_Version) $\% 20$ (Blackline).pdf

Maitra, K., \& Erway, F. (2006). Perceptions of client centred practice in Occupational Therapists and their clients. The American Journal of Occupational Therapy, 60(3): 298-310.

Mangusan, D. (2014). Physiotherapy notes-PT notes. Retrieved from http:/ / www.physiotherapynotes.com/2011/03/ parts-physiotherapy-soap-notes.html

Mann, K.V., McFetridge-Durdle, J., Martin-Misener, R., Clovis, J., Rowe, R., Beanands, H., et al. (2009). Interprofessional education for students of the health professions: The "seamless care" model. Journal of Interprofessional Care, 23(3), 224-233.

Masterson, A. (2007). Community matrons: Inter-professional and inter-agency working (part five). Nursing Older People, 19(8), 38-40.

McBride, L., \& Walden-McBride, D. (1995). Balancing the 'heart' of patient care. Home Healthcare Nurse, 13(4), 46-49.

McCance, T, McCormack, B, \& Dewing, J. (2011). An exploration of person-centredness in practice. Online Journal of Issues in Nursing, 16(2), 1.

McCallin, A., \& McCallin, M (2009). Factors influencing team working and strategies to facilitate successful collborative teamwork. New Zealand Journal of Physiotherapy, $37(2), 61-67$.

McCormack, B. (2003). A conceptual framework for personcentred practice with older people. International Journal of Nursing Practice, 9(3), 202-209.

McCormack, B. (2004). Person-centredness in gerontological nursing: An overview of the literature. Journal of Clinical Nursing, 13(3a), 31-38.

McSkimming, S., London, M. R., Lieberman, C., Quinn, C., \& Carney, B. (2004). A "CALL" for community-focused palliative care. Care Management Journals, 5(3), 167-173.

Microsoft (2010). Microsoft Excel [computer software]. Redmond, Washington: Microsoft.

Mitchell, G. J., Bournes, D. A., \& Hollett, J. (2006). Human becoming-guided patient-centred care: A new model transforms nursing practice. Nursing Science Quarterly, 19(3), 218-224.

Moe, A., Ingstad, K., \& Brataas, H. V. (2017). Patient influence in home-based reablement for older persons: Qualitative research. BMC Health Services Research, 17(1): 736 doi:10.1186/s12913-017-2715-0.
Nandram, S., \& Koster, N. (2014). Organizational innovation and integrated care: Lessons from Buurtzorg. Journal of Integrated Care, 22(4), 174-184.

Nolan, M. R., Brown, H., Davies, S., Nolan, J., \& Keady, J. (2006). The Senses Framework: Improving care for older people through a relationship-centred approach. Getting Research into Practice (GRiP) Report No 2. Project Report. Sheffield, United Kingdom: University of Sheffield.

Nolan, M. R., Davies, S., Brown, J., Keady, J., \& Nolan, J. (2004). Beyond person-centred care: A new vision for gerontological nursing. Journal of Clinical Nursing, 13(3a), 45-53.

North York General Hospital. (2015). Patient and familycentred care at North York General. Retrieved from http:/ / www.nygh.on.ca/Default.aspx?cid=2474\&lang=1

Nova Scotia Physiotherapy Association. (2015). About physiotherapy-scope of practice. Retrieved from http:/ / www.physiotherapyns.ca/index.php/site/about_ physio_scope/

Ontario Association of Community Care Access Centres. (2014). Expanding patient-centred in-home physiotherapy services to support a range of patient needs and goals. Retrieved from http:/ / oaccac.com/Who/ Conference/Documents/June\%209,\%202014/MA01TheNewPhysiotherapyModel.pdf

Oxtoby, M., \& Eikaas, M. (1993). Multidisciplinary management from day one: The Neuro-care approach to motor neurone disease. Palliative Medicine, 7(4), 31-36.

Parse, R. R. (1992). Human becoming: Parse's theory of nursing. Nursing Science Quarterly, 5(1), 35-42.

Pawson, R., Greenhalgh, T., Harvey, G., \& Walshe, K. (2004). Realist synthesis: An introduction. Manchester, United Kingdom: ESRC Research Methods Program.

Phillips, S. D., Burns, B. J., Edgar, E. R., Mueser, K. T., Linkins, K. W., Rosenheck, R. A., et al. (2001). Moving assertive community treatment into standard practice. Psychiatric Services, 52(6), 771-779.

Pizzimenti, J. J., \& Roberts, E. (2005). The low vision rehabilitation service. Part two: Putting the program into practice. Internet Journal of Allied Health Sciences \& Practice, 3(3), Article 5.

Prince Edward Island Occupational Therapy Society. (n.d.) What is occupational therapy? Retrieved from http:// www.peiot.org/society/society-what-is-ot

Providence Healthcare. (2015). Mission, vision and values. Retrieved from http:/ /www.providencehealthcare.org/ about-providence/who-we-are/mission-vision-values

Radhakrishnan, K., Xie, B., \& Jacelon, C.S. (2016). Unsustainable home telehealth: A Texas qualitative study. The Gerontologist, 56(5): 830-840.

Registered Nurses Association of Ontario. (2015). Nursing best practice guideline: Person and family-centred care. Toronto: Author. 
Ryburn, B., Wells, Y., \& Foreman, P. (2009). Enabling independence: Restorative approaches to home care provision for frail older adults. Health and Social Care in the Community, 17(3), 225-234.

Rycroft-Malone, J., McCormack, B., Hutchinson, A. M., DeCorby, K., Bucknall, T.K., Kent, B., et al. (2012) Realist synthesis: Illustrating the method for implementation research. Implementation Science, 19(7), 33.

Sabus, C., Sabata, D., \& Antonacci, D. (2011). Use of a virtual environment to facilitate instruction of an interprofessional home assessment. Journal of Allied Health, 40(4), 199-205.

Saint Elizabeth Health Care. (2015a). About Saint Elizabeth. Retrieved from https:/ / www.saintelizabeth.com/AboutSaint-Elizabeth.aspx

Saint Elizabeth Health Care. (2015b). Saint Elizabeth's Person and Family-Centred Care Institute. Retrieved from https: / / www.saintelizabeth.com/Services-andPrograms/Research-Centre/Person-and-Family-CentredCare-Institute.aspx

Snayde, F., \& Moriarty, J. (2009). Person-centred home care for people with dementia: Developing a specialist service in an ethnically diverse community. Dementia, 8(1), 148-152.

Stefanacci, R. G. (2013). Care coordination today: What, why, who, where, and how? Annals of Long Term Care, 21(3), 38-42.

Stucki, G. (2005). International classification of functioning, disability, and health (ICF): A promising framework and classification for rehabilitative medicine. American Journal of Physical Medicine $\mathcal{E}$ Rehabilitation, 84, 733-740.

Sumsion, T., \& Law, M. (2006). A review of evidence on the conceptual elements informing client-centred practice. Canadian Journal of Occupational Therapy Revue Canadienne d'Ergotherapie, 73(3), 153-162.

Szanton, S. L., Wolff, J. L., Leff, B., Roberts, L., Thorpe, R. J., Tanner, E. K., et al. (2015). Preliminary data from community aging in place, advancing better living for elders, a patient-directed, team-based intervention to improve physical function and decrease nursing home utilization: The first 100 individuals to complete a centers for Medicare and Medicaid services innovation project. The Journal of the American Geriatrics Society, 63(2), 371-374.

Toscan, J. L., Mairs, K., Hinton, S., \& Stolee, P. (2012). Integrated transitional care: Patient, informal caregiver and health care provider perspectives on care transitions for older persons with hip fracture. International Journal of Integrated Care, 12, E13.

Townsend, E. A., \& Polatajko, H. J. (2007). Enabling occupation II: Advancing an occupational therapy vision for health, well-being \& justice through occupation. Ottawa: Canadian Association of Occupational Therapists.

Vik, K., Lilja, M., \& Nygard, L. (2007). The influence of the environment on participation subsequent to rehabilitation as experienced by elderly people in Norway. Scandinavian Journal of Occupational Therapy, 14, 86-95.

Watson Caring Science Institute. (2010). Core concepts of Jean Watson's theory of human caring/caring science. Retrieved from http:/ / watsoncaringscience.org/files / Cohort $\% 206 /$ watsons-theory-of-human-caring-coreconcepts-and-evolution-to-caritas-processes-handout.pdf

Watson, J., \& Woodward, T.K. (2010). Jean Watson's theory of human caring. Nursing Theories and Nursing Practice, 3, 351-369.

Welsh, T. J., Gordon, A. L., \& Gladman, J. R. (2014). Comprehensive geriatric assessment-A guide for the non-specialist. International Journal of Clinical Practice, 68(3), 290-293.

Wong, G., Greenhalgh, T., Westhorp, G., Buckingham, J., \& Pawson, R. (2013). RAMSES publication standards: Realist synthesis. BMC Medicine, 11, 21.

World Health Organization. (2001). International classification of functioning, disability and health: Geneva: Author. 


\section{Appendix A: Interview Guide for Step 2 of Search Strategy}

Thank you for agreeing to speak with me today.

As per the e-mail I sent, we are exploring how personand family-centred care (PFCC) is delivered to geriatric clients by interdisciplinary home care teams involving nurses, occupational therapists (OTs) and/or physiotherapists (PTs).

This is not a formal research interview-we are not recording the conversation-nothing you say will be quoted in any reports stemming from this research.

The purpose of this call is to get your guidance as an expert in your discipline of [nursing/occupational therapy/ physiotherapy] as to what literature (both published and grey), practice guidelines, other resources, and tools we should review to understand how PFCC is/should be delivered by [nurses/OTs/PTs] in geriatric home care.

What PFCC resources are you aware of? / do you use? / do you believe other [nurses/OTs/PTs] use to guide practice? [Probes: see discipline- specific theories in evaluative framework; four components of PFCC: participation, collaboration, information sharing, dignity and respect; and be sure to get author, name, link, or other identifying information so that resource can be found afterwards.]

Are you aware of any PFCC resources that discuss how to implement PFCC in the context of an interdisciplinary care team?

Thank you for your time-is there anyone else in your discipline whom we should speak to about this? / do you feel that would be able to point us to additional sources on PFCC in [nursing/OT/PT]?

Would you be interested in being e-mailed a copy of the final report resulting from this research?

We intend to acknowledge you in our final report/ publication as an expert providing information for the search - would this be okay with you or would you prefer to not be named? (If yes, confirm spelling, degrees, affiliations, and title)

Thank you for your time.

\section{Appendix B: Inclusion/ Exclusion Criteria for Phase 3: Database Searching}

1. Is the article relevant to home and/or community care?

- Home or community is defined as:

- Individual's private residence where the person lives at least somewhat independently-home/ apartment, retirement home, assisted living

- Primary care-if person-centred medical home and/ or primary care is discussed as a concept/philosophy of care or if home care is discussed within a personcentred medical home/ primary care model

- Home and community is not:

- Nursing home, care home (UK)

- Long-term care facility/ home

- Primary health centres-clinics, family health teams, physician office, community health centres

2. Relevance to Geriatric care:

- Does the article specify population?

- If yes, is the population composed at least partially of older adults? (elderly, elder older, senior, frail, mature, )

- If no, could knowledge from the article be applied to geriatric home care? (e.g., theoretical, editorial, patient groups such as for those with dementia)

3. Is at least one of the following disciplines mentioned in the article as collaborating with another type of provider?

- Nurses?

- OTs?

- PTs?

4. Relevance to PFCC:

- Does the article discuss one or more of the four key components of PFCC described below?

- Dignity and respect. Health care practitioners listen to and honor patient and family perspectives and choices. Patient and family knowledge, values, beliefs, and cultural backgrounds are incorporated into the planning and delivery of care.

- Information sharing. Health care practitioners communicate and share complete and unbiased information with patients and families in ways that are affirming and useful. Patients and families receive timely, complete, and accurate information in order to effectively participate in care and decision making.

- Participation. Patients and families are encouraged and supported in participating in care and decision making at the level that they choose.

- Collaboration. Patients, families, health care practitioners, and leaders collaborate in policy and program development, implementation, and evaluation; in health care facility design; and in professional education, as well as in the delivery of care (Institute for Patient and Family Centred Care [2010], para. 4).

- If yes, does the article address PFCC at the point-ofcare (or influence the point-of-care; for example, education, organizational policies and procedures)?

5. Quality appraisal (see Critical Appraisal Skills Program [CASP] tool for more details)

- Is there a clear statement of the aims of the article?

- Is the methodology appropriate (qualitative, quantitative, review) for research studies?

- Design

- Data collection

- Recruitment

- Relationship between researcher and participants - Ethics

- Is there a clear statement of findings/ conclusions?

- Does this article add new knowledge/ value to the topic of interdisciplinary PFCC? 


\section{Appendix C: Data Abstraction-Information Captured}

\begin{tabular}{|c|c|c|c|c|}
\hline Reference Characteristics & Research Methods & Background (Context) & Findings (Outcomes) & $\begin{array}{l}\text { Explanation/Interpretation } \\
\text { (Mechanism) }\end{array}$ \\
\hline $\begin{array}{l}\text { - Reviewer } \\
\text { - Title } \\
\text { - Authors } \\
\text { - Year of publication } \\
\text { - Country } \\
\text { - Type of article (research, } \\
\text { editorial) } \\
\text { - Purpose of the article } \\
\text { - Geriatric relevance* } \\
\text { - Home care relevance* }\end{array}$ & $\begin{array}{l}\text { - Study design (randomized } \\
\text { controlled trial [RCT], case } \\
\text { study, pilot, qualitative/ } \\
\text { quantitative) } \\
\text { - Data collected (interviews, } \\
\text { surveys, outcome measures) } \\
\text { - Program/ theoretical } \\
\text { approach }\end{array}$ & $\begin{array}{l}\text { Interdisciplinary collaboration* } \\
\text { - Health care providers of } \\
\text { interest involved (nurse, OTs, } \\
\text { PTs) and their role } \\
\text { - Other health care providers } \\
\text { involved } \\
\text { - Communication/ collaboration } \\
\text { PFCC* } \\
\text { - Dignity and respect } \\
\text { context/ mechanism } \\
\text { - Information sharing } \\
\text { - Participation } \\
\text { - Collaboration } \\
\text { Home care setting }\end{array}$ & $\begin{array}{l}\text { - Results from pilot testing/ } \\
\text { RCTs of PFCC programs } \\
\text { and/or interventions }\end{array}$ & $\begin{array}{l}\text { - Description of activities of } \\
\text { PFCC programs and/or } \\
\text { interventions } \\
\text { - Contributions to our } \\
\text { understanding of team- } \\
\text { based PFCC (how and } \\
\text { why PFCC works) } \\
\text { - Recommendations / } \\
\text { conclusions made by author } \\
\text { - System level supports (policy, } \\
\text { practice, education) }\end{array}$ \\
\hline
\end{tabular}

\footnotetext{
* Include only if all the information is captured.
} 